\title{
Quaternary Ammonium-Based Room Temperature Ionic Liq- uids as Components of Carbonate Electrolytes for Li-ion Batter- ies: Electrochemical Performance and Thermal Properties
}

\author{
Denis V. Chernyshov* and Woo Cheol Shin \\ Energy 2 Laboratory, Battery R\&D, Samsung SDI Co. Ltd., Samsung-ro, Suwon 443-803, Republic of Korea
}

\begin{abstract}
Electrochemical performance of Li-ion cells with $\mathrm{LiMn}_{2} \mathrm{O}_{4}$ cathodes and graphite anodes with carbonates electrolytes containing quaternary ammonium-based room temperature ionic liquids (ILs) is investigated. Eight different ILs based on tetraalkylammonium, pyrrolidinium or piperidinium cations paired with bis(trifluoromethylsulfonyl)imide or tris(pentafluoroethyl)trifluorophosphate anions are examined in combination with dimethyl carbonate as a main solvent and fluoroethylene carbonate as a solid electrolyte interface forming agent. It is shown that cycling properties of the cells are strongly affected by the content of ILs in the electrolyte mixtures and its increase corresponds to lower discharge capacity retention. Since viscosity and conductivity of ILs are of a great importance for the electrolytes formulation, some kind of combined parameter should be used for the assessment of IL applicability and calculated values of Walden products for neat ILs represent one of the possible options. Besides, positive effect of ILs on reduction of flammability and enhancement of thermal stability of electrolytes in contact with charged electrodes have been demonstrated by means of self-extinguishing time test and differential scanning calorimetry respectively.
\end{abstract}

Keywords: Ionic liquids; Electrolyte; Thermal stability; Lithium-ion battery.

Received December 8, 2013 : Revised January 9, 2014 : Accepted January 20, 2014

\section{Introduction}

Lithium-ion batteries (LIB) have been already used successfully as a key components of portable electronic devices, however, during the last years a special attention is given to the extending the use of LIB for applications as a large-scale power sources [1]. In turn, this leads to formulation of specific standards for the cycling performance and safety characteristics of the cells. Among different actual research trends, operating at a high voltage [2] or/and enhancement of thermal stability of the LIB are of particular impor- tance [3]. Undoubtedly, many undesirable processes may affect the whole thermal stability but one of the governing factors is the thermal decomposition of electrolyte in contact with the surfaces of charged electrodes [3,4]. On the other hand, insufficient electrochemical stability of electrolyte usually causes its cathodic or anodic decomposition at low or high potentials respectively which also may be problematic in terms of both capacity loss and safety [5]. In this relation, use of electrolyte components with enhanced thermal and electrochemical stability seems reasonable and one of the possible ways is the

*Corresponding author. Tel.: +82-31-8061-2421

E-mail address: den.chernyshov@gmail.com

Open Access DOI: http://dx.doi.org/10.5229/JECST.2014.5.4.95

This is an Open Access article distributed under the terms of the Creative Commons Attribution Non-Commercial License (http://creativ ecommons.org/licenses/by-nc/3.0/) which permits unrestricted non-commercial use, distribution, and reproduction in any medium, provided the original work is properly cited. 
application of ionic liquids (ILs; organic salts with melting points below $100^{\circ} \mathrm{C}$, often below $0^{\circ} \mathrm{C}$ ) as a replacement of traditional solvents of standard carbonate electrolytes [6]. Ionic liquids possess a unique combination of attractive properties (wide liquidity range, negligible vapor pressure, high decomposition temperatures, ionic conductivity, wide electrochemical window, etc.) which may be varied via changing of constituent ions [7]. Nevertheless, despite the growing interest to ILs for Li batteries applications [8-10], some factors still limit their utilization. Since different constituent cations of ILs may both decompose at low potentials $[11,12]$ or intercalate into graphite anode electrode [13-16], a stable solid electrolyte interface (SEI) should be formed prior to these interfering processes may occur and the use of an appropriate additives remains actual [13,16-20]. At the same time, even in case of electrochemically stable ILs, viscosity of ILs is incomparably higher (2-3 orders of magnitude) than for standard carbonate solvents and this affects strongly the power properties of the cells $[9,10,21,22]$. Finally, the cost of ILs is still quite high and it's another limitation. Probably, utilization of ILs in combination with traditional carbonate electrolyte components (instead of complete replacement) may be considered as some compromise approach [16,23-25].

This study represents an investigation of the elec- trochemical properties of Li/graphite and graphite/ $\mathrm{LiMn}_{2} \mathrm{O}_{4}$ cells cycled in ILs-based carbonate electrolytes. Different quaternary ammonium-based room temperature ILs, which are known as electrochemically stable, have been combined with low-viscous dimethyl carbonate (DMC; used as a main solvent) [5] and fluoroethylene carbonate (FEC) as stable SEI-forming additive [16,25-27].

\section{Experimental}

2.1. Chemical reagents and electrolytes preparation Ionic liquids 1-propyl-1-methylpyrrolidinium bis(trifluoromethylsulfonyl)imide (PMPL-TFSI; >99\%), 1-propyl-1-methylpiperidinium bis(trifluoromethylsulfonyl) imide (PMPip-TFSI; >99\%), trimethylpropylammonium bis(trifluoromethylsulfonyl)imide (TMPA-TFSI; $>99 \%$ ), and triethylhexylammonium bis(trifluoromethylsulfonyl)imide (TEHA-TFSI; >99\%) were provided by Toyo Gosei Co. Ltd., Japan; $N$-ethyl- $N, N$-dimethyl(2-methoxyethyl)ammonium tris(pentafluoroethyl)trifluorophosphate (MOEDEA-FAP; >99\%), 1-(2-methoxyethyl)-1-methylpyrrolidinium tris(pentafluoroethyl) trifluorophosphate (MOEMPL-FAP; >99\%), 1-butyl-1methylpyrrolidinium bis(trifluoromethylsulfonyl) imide (BMPL-TFSI; >98\%), and 1-butyl-1-methylpyrrolidinium tris(pentafluoroethyl)trifluorophosphate (BMPLFAP; $>98 \%$ ) were provided by Merck KGaA, Germany
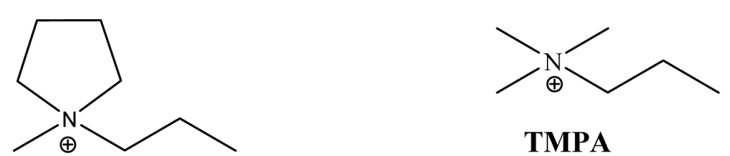

PMPL<smiles>CCCCCC[N+](CC)(CC)CC</smiles>

TEHA<smiles>CCC[Nb]1(C)CCCCC1</smiles>

PMPip

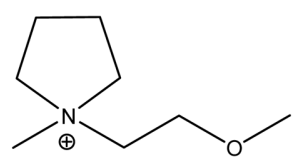

MOEMPL

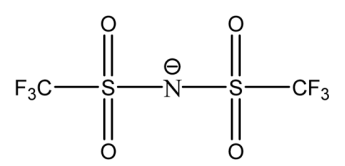

TFSI

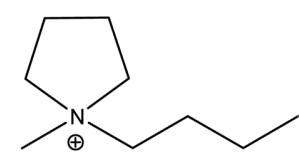

BMPL<smiles>CC[Nb](C)(C)CCOC</smiles>

MOEDEA<smiles>FC(F)(F)C(F)(F)C(F)(F)C(F)(F)C(F)(F)C(F)(F)C(F)(F)P(F)(F)(C(F)(F)F)C(F)(F)C(F)(F)F</smiles>

FAP

Fig. 1. Chemical structures of ionic liquids investigated in the present work. 
(see Fig. 1). Dimethylcarbonate (DMC), fluoroethylene carbonate (FEC), and lithium hexafluorophosphate $\left(\mathrm{LiPF}_{6}\right)$ were provided by Cheil Industries Inc. All chemicals were used as received, without further purification.

For electrolytes preparation, DMC was used as a main low-viscous solvent and FEC in 10 vol. \% concentration was used as a solid electrolyte interface (SEI) forming agent while the content of ionic liquids varied from 0 to 40 vol. \%; $1 \mathrm{M} \mathrm{LiPF}_{6}$ concentration was used in all cases. For investigation of thermal properties of electrolytes in contact with lithiated graphite or delithiated $\mathrm{LiMn}_{2} \mathrm{O}_{4}$, a standard $1 \mathrm{M} \mathrm{LiPF}_{6}$ solution in EC/EMC (3/ 7 , v/v; Cheil Industries Inc.) was used for galvanostatic charging of $\mathrm{Li} /$ graphite or $\mathrm{Li} / \mathrm{LiMn}_{2} \mathrm{O}_{4}$ coin half cells.

\subsection{Electrodes preparation and cells fabrication}

To evaluate the electrochemical properties of graphite electrodes, a slurry was prepared by mixing of $97.5 \mathrm{wt} . \%$ graphite as an active material with $1.5 \mathrm{wt} . \%$ styrene-butadiene rubber (SBR) and $1 \mathrm{wt}$ \% carboxymethylcellulose (sodium salt; CMC) as a binder in a distilled deionized water. The resulting slurry was cast on a copper foil and the composite electrode was dried in a vacuum oven at $110^{\circ} \mathrm{C}$ overnight. The electrode was pressed to a thickness of approximately $50 \mu \mathrm{m}$ in order to obtain proper electronic conductivity. The loading of active materials in the anode corre-

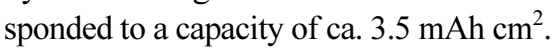

The cathode had a composition of $90 \mathrm{wt}$. \% lithium manganese oxide $\left(\mathrm{LiMn}_{2} \mathrm{O}_{4}\right), 5$ wt. $\%$ of carbon black (Super-P, Superior graphite, USA) and 5 wt. \% of PVdF (Aldrich). The cathode sheets were fabricated by spreading the slurry (suspension of $\mathrm{LiMn}_{2} \mathrm{O}_{4}$ powder and carbon black in a PVdF/N-methyl-2-pyrrolidone solution) on an aluminum foil current collectors with a doctor blade device and then dried in a vacuum oven at $110^{\circ} \mathrm{C}$ overnight. The loading of active materials in the cathode

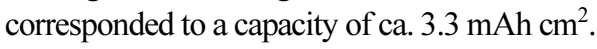

Coin-type cells CC2016 (diameter $20 \mathrm{~mm}$, height $1.6 \mathrm{~mm}$ ) for $\mathrm{Li} /$ graphite (or $\mathrm{Li} / \mathrm{LiMn}_{2} \mathrm{O}_{4}$ ) half cells and CR2032 (diameter $20 \mathrm{~mm}$, height $3.2 \mathrm{~mm}$ ) for graphite/ $\mathrm{LiMn}_{2} \mathrm{O}_{4}$ full cells were assembled in an Ar-filled glove box with less than $1 \mathrm{ppm}$ of oxygen and moisture. For the cell assembly, polypropylene (Celgard) separators were soaked in the electrolytes to be examined.

\subsection{Electrochemical measurements}

Linear sweep voltammetry was carried out using a three-electrode voltammetry cell (VC-4, BioLogic,
France) with Pt disk electrode (internal diameter $1.6 \mathrm{~mm}$ ) as a working one, Pt wire as a counter electrode and Li foil as a reference electrode. Cathodic and anodic polarization was performed in the potential ranges between $(-0.5 \div 4 \mathrm{~V})$ and $(4-6.5 \mathrm{~V})$ vs. $\mathrm{Li} / \mathrm{Li}^{+}$respectively with a scan rate of $25 \mathrm{mV} \mathrm{s}^{-1}$ using an Autolab PGSTAT302N.

Cycling tests were galvanostatically performed between $0.01-1.0 \mathrm{~V}$ (vs. $\mathrm{Li} / \mathrm{Li}^{+}$) for $\mathrm{Li} /$ graphite half cells and $2.8-4.2 \mathrm{~V}$ for graphite/ $\mathrm{LiMn}_{2} \mathrm{O}_{4}$ full cells at a rate of $0.1 \mathrm{C}$ for the first formation cycle and $0.5 \mathrm{C}$ for the subsequent cycles using a computer-controlled battery measurement system (TOSCAT $3000 \mathrm{U}$ ) .

\subsection{Thermal analysis}

For measuring the self-extinguishing time (SET), pre-weighed samples of the electrolyte solutions (typically, ca. $0.3 \mathrm{~g}$ ) placed into stainless steel can (diameter $20 \mathrm{~mm}$ ) were ignited and the time it took for the flame to extinguish was recorded. The SET parameter was obtained by normalizing the flame burning time against the electrolyte mass.

To measure the thermal properties of lithiated graphite (or delithiated $\mathrm{LiMn}_{2} \mathrm{O}_{4}$ ) with electrolytes, coin half cells were charged to a potential of $0.01 \mathrm{~V}$ (or, in case of $\mathrm{LiMn}_{2} \mathrm{O}_{4}$, to $4.3 \mathrm{~V}$ ) vs. $\mathrm{Li} / \mathrm{Li}^{+}$and then carefully opened in a dry room. The retrieved electrodes were rinsed in DMC solvent to remove residual electrolyte and dried under a vacuum. The resulting lithiated graphite (or delithiated $\mathrm{LiMn}_{2} \mathrm{O}_{4}$ ) electrodes were sealed together with electrolytes in a hermetic stainless-steel pans (Perkin Elmer). All of the differential scanning calorimetry (DSC) measurements were carried out at a heating rate of $10^{\circ} \mathrm{C} \mathrm{min}{ }^{1}$ over a range of $25-400^{\circ} \mathrm{C}$ using TA Instruments Auto Q20 differential scanning calorimeter. The amount of an entrapped electrolyte was $30 \mathrm{wt}$. \% based on the electrode powder. Thermogravimetric analysis (TGA) of TMPA-TFSI was carried out under a dry nitrogen atmosphere at a heating rate of $5^{\circ} \mathrm{C} \min ^{1}$ over range from 25 to $500^{\circ} \mathrm{C}$ using TA Instruments SDT Q600 simultaneous TGA/DSC-meter.

\section{Results and Discussion}

For the preparation of mixed carbonate electrolytes, quaternary ammonium-based ILs with TFSI or FAP anions have been selected (Fig. 1); some of the physical properties of investigated ILs are presented 
Table 1. Physical properties of ionic liquids investigated: melting point $\left(T_{m}\right)$, molar weight $(M)$, density $(\rho)$, specific conductivity $(\sigma)$, viscosity $(\eta)$, IL concentration $\left(C_{I L}\right)$, molar conductivity $\left(\Lambda=\sigma / C_{\text {IL }}\right)$ and Walden product $(\Lambda \eta)$

\begin{tabular}{|c|c|c|c|c|c|c|c|c|c|}
\hline \multirow[b]{2}{*}{ Ionic liquid } & \multirow[b]{2}{*}{$\mathrm{Tm},{ }^{\circ} \mathrm{C}$} & \multirow[b]{2}{*}{$\mathrm{M}, \mathrm{g} / \mathrm{mol}$} & \multicolumn{3}{|c|}{ Measured at $25^{\circ} \mathrm{C}$} & \multirow[b]{2}{*}{ Ref } & \multicolumn{3}{|c|}{ Calculated } \\
\hline & & & $\rho, \mathrm{g} / \mathrm{cm}^{3}$ & $\sigma, \mathrm{mS} / \mathrm{cm}$ & $\eta, \mathrm{cP}\left(0.1 \mathrm{Ns} / \mathrm{m}^{2}\right)$ & & $\mathrm{C}_{\mathrm{IL}}, \mathrm{mol} / \mathrm{dm}^{3}$ & $\begin{array}{c}\Lambda, \\
\mathrm{cm}^{2} / \Omega \mathrm{mol}\end{array}$ & $\begin{array}{c}\Lambda \eta, \\
10^{-7} \mathrm{Ns} / \Omega \mathrm{mol}\end{array}$ \\
\hline PMPL-TFSI & 12 & 408 & 1.45 & 1.4 & 63 & [28] & 3.6 & 0.39 & 25 \\
\hline BMPL-TFSI & -18 & 422 & 1.41 & 2.2 & 85 & [28] & 3.3 & 0.66 & 56 \\
\hline PMPip-TFSI & 12 & 422 & 1.43 & 1.4 & 151 & {$[8,12]$} & 3.4 & 0.41 & 62 \\
\hline TMPA-TFSI & 19 & 382 & 1.44 & 3.3 & 72 & {$[8,11]$} & 3.8 & 0.88 & 63 \\
\hline TEHA-TFSI & 20 & 466 & 1.27 & 0.67 & 167 & {$[28]$} & 2.7 & 0.25 & 41 \\
\hline MOEDEA-FAP & $<-50$ & 577 & $1.63(20)$ & $1.1(20)$ & $178(20)$ & [30] & 2.8 & 0.39 & 69 \\
\hline MOEMPL-FAP & $<-50$ & 589 & $1.65(20)$ & $1.3(20)$ & $164(20)$ & {$[30]$} & 2.8 & 0.46 & 76 \\
\hline BMPL-FAP & 4 & 587 & $1.59(20)$ & $0.9(20)$ & $292(20)$ & {$[30]$} & 2.7 & 0.33 & 97 \\
\hline
\end{tabular}

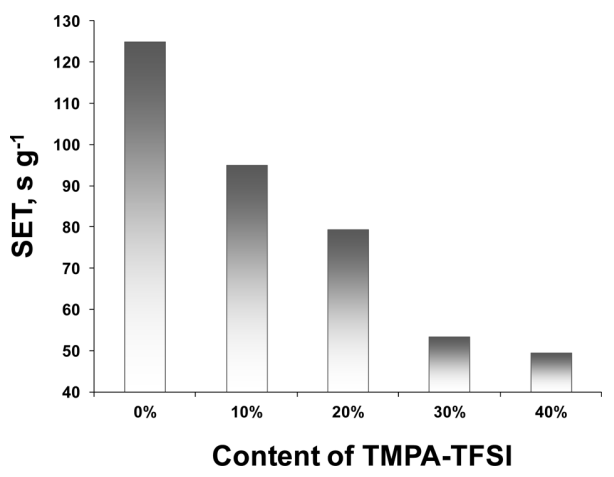

Fig. 2. The results of flammability test of SET for electrolyte solutions containing $1 \mathrm{M} \mathrm{LiPF}_{6}$ in $\mathrm{DMC}$ in presence of both 10 vol. \% FEC and different concentrations of TMPA-TFSI.

in Table 1. Since the main reason for introducing the ionic liquids as co-solvents into electrolyte mixtures is the intent to improve the safety and, in particular, to decrease the electrolyte's flammability, prior to all electrochemical measurements an estimative selfextinguishing time (SET) test has been performed. Different authors have reported that for quaternary ammonium-based ILs a concentration range of ca. $30-40 \%$ is optimal for significant reduction or, in some cases, even for complete suppression of flammability of mixed electrolytes [16,23-25]. Typical, dependence of SET on IL's content is given on Fig. 2. As is seen, the higher the IL's concentration, the lower the flammability - thus, due to the presence of 30 vol. $\%$ of TMPA-TFSI a noticeable reduction of flammability of electrolyte has been achieved (ca. $60 \%$ decrease of SET parameter in comparison with similar IL-free mixture). At the same time, further increase of IL's content up to 40 vol. \% does not provide a significant improvement. Noteworthy, while the absolute values of SET may slightly vary for ILs of different structures, the general trend remains the same so for further tests the concentration for all ILs has been chosen as 30 vol. \% since this content had been found to be adequate for decrease of flammability in order to meet some safety requirements.

While selecting of an appropriate structures of ILs to be utilized in LIB, one should realize that, likely, the most important property of ILs as co-solvents for electrolytes is their electrochemical stability which should definitely match the voltage ranges typical for LIB-chemistry. Generally, cathodic or anodic decomposition of ILs is determined mainly by the nature of cations or anions respectively [8]. In present work salts of tetraalkylammonium-, dialkylpyrrolidinium- and dialkylpiperidinium-cations are selected as they possess a cathodic stability which is seemed to be suitable for LIB-applications [8-11]. Although the introduction of alkoxy-groups into cation's structure causes not only the reducing of IL's viscosity but also a slight decrease of electrochemical window in cathodic region [12], this negative effect is not so significant and, therefore, MOEDEA and MOEMPL cations may be considered as appropriate ones, especially for the use in presence of FEC [16,25-27]. Concerning the tolerance towards higher voltages, FAP-anions have been reported to provide a very good anodic stability for corresponding ILs, even higher than for $\mathrm{PF}_{6}$ - and TFSI-salts [31,32]. Larush et al. have clearly demonstrated that presence of ILs containing tetraalkylammonium- or dialkylpyrrolidinium-cations 
and TFSI- or FAP-anions does not shorten the electrochemical 'windows' for mixed carbonates-ILs electrolytes so from this point of view the choice of the structures selected for present work is seemed rational [32]. On the other hand, a certain chemical compatibility between the constituent cations or anions of ILs and materials used for the cells fabrication is absolutely mandatory. For example, it is wellknown that LiTFSI is not an ideal replacement for $\mathrm{LiPF}_{6}$ because of pronounced corrosion of $\mathrm{Al}$ current collector [33] so a specific attention towards ILs containing TFSI-anion is pretty expectable. However, it has been reported that TFSI-containing ionic liquids not only do not cause corrosion of Al but also are able to suppress it significantly if an excess of LiTFSI is used [34]. Moreover, it has been found that presence of $\mathrm{LiPF}_{6}$ also inhibits $\mathrm{Al}$ corrosion caused by TFSI [35]. In total, in a given experimental conditions ( 30 vol. $\%$ of ILs in a mixture, $1 \mathrm{~mol} \mathrm{dm}^{-3}$ concentration of $\mathrm{LiPF}_{6}$ as a main electrolyte, ambient temperature, moderate voltage range) corrosion of $\mathrm{Al}$ caused by TFSI-containing ILs is not supposed to be

(a)

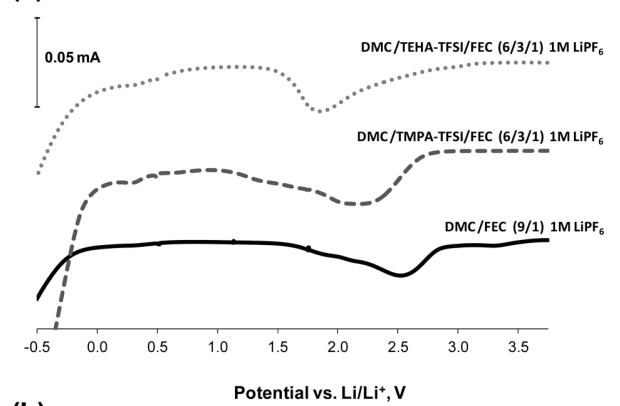

(b)

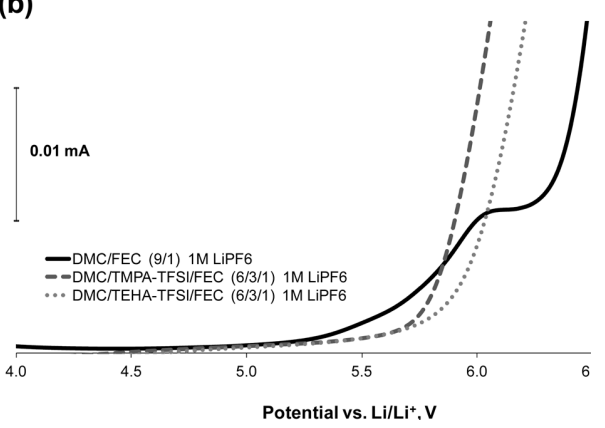

Fig. 3. Linear sweep voltammetry data for the electrolytes containing $10 \mathrm{vol}$ \% FEC and no IL or $30 \mathrm{vol}$ \% of TMPATFSI or TEHA-TFSI: a) cathodic polarization; b) anodic polarization; working electrode - Pt disk, counter electrode $\mathrm{Pt}$ wire; reference electrode - Li foil; scan rate $25 \mathrm{mV} \mathrm{s}^{-1}$. an issue. Hence, the expected total electrochemical stability of mixed 1M LiPF 6 DMC / IL / FEC electrolytes has been estimated as suitable for the working voltage range $(2.8-4.2 \mathrm{~V}$ for full cells).

Typical linear sweep voltammograms for some examples of TFSI-containing ILs are given on Fig. 3. As is seen, an introduction of ILs does not impair the cathodic stability of electrolytes and the only difference detected is a certain shift of the signal of FECreduction to the lower potentials (Fig. 3a) which is caused by the presence of relatively viscous ILs in electrolyte mixtures (for viscosity of pure ILs refer Table 1). On the other hand, presence of ILs does not affect the anodic stability of electrolytes as well and the only differences may be detected at high potentials which are far beyond the working voltage range used in a present work (Fig. 3b).

The first charge and discharge curves of the $\mathrm{Li} /$ graphite coin half cells are given in Fig. 4. As is seen, in comparison with FEC-free DMC-electrolyte (Fig. $4 \mathrm{a})$, the presence of 10 vol. \% FEC increases the reversible capacity from 340 to $350 \mathrm{mAh} \mathrm{g}^{-1}$ and initial Coulombic efficiency from 90 to $92 \%$ respec-

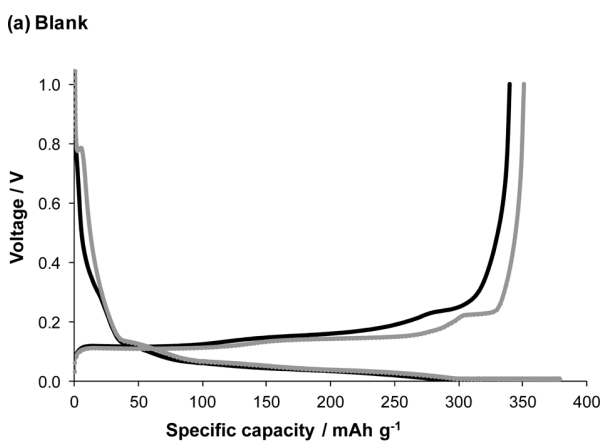

(b) TMPA-TFS

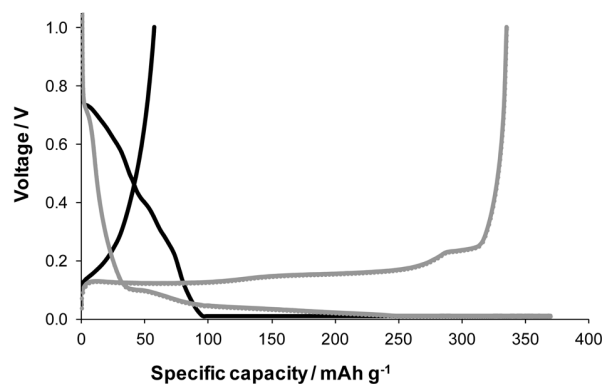

Fig. 4. Charge and discharge curves of Li/graphite coin half cells during $1^{\text {st }}$ cycle at $0.1 \mathrm{C}$ : a) electrolytes without IL; b) with 30 vol. \% TMPA-TFSI; black lines - without FEC, gray lines - with 10 vol. \% FEC. 
(a)

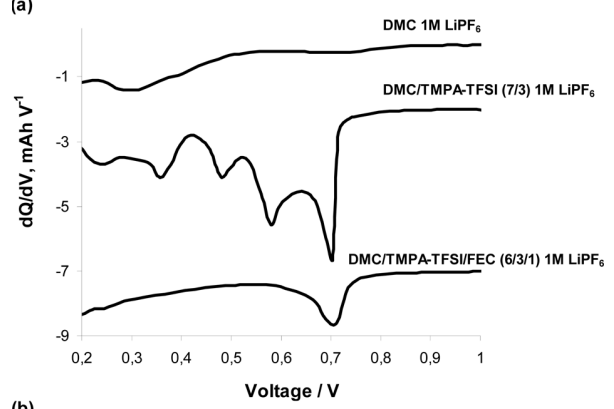

(b)

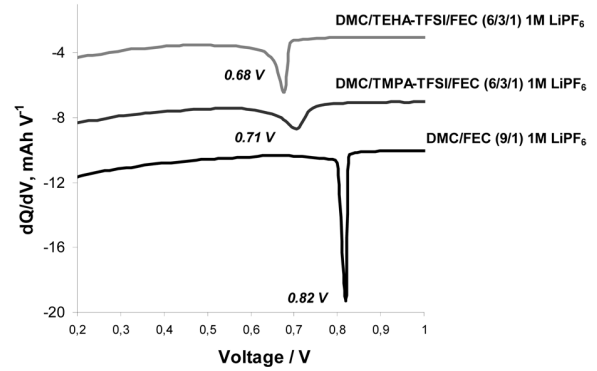

Fig. 5. $d \mathrm{Q} / \mathrm{dV}$ graphs of $\mathrm{Li} /$ graphite coin half cells during $1^{\text {st }}$ cycle at $0.1 \mathrm{C}$ : a) effects of TMPA-TFSI and FEC; b) shift of characteristic FEC-reduction peak to lower potentials depending on whole electrolyte's formulation.

tively. At the same time, effect of FEC is more significant in the case of IL-containing electrolyte (Fig. 4b). Use of electrolyte containing 30 vol.\% TMPA-TFSI without FEC results in extremely low reversible capacity of $57 \mathrm{mAh} \mathrm{g}^{-1}$ and initial Coulombic efficiency of $15 \%$ while for similar FEC-containing electrolyte characteristics demonstrated are much more optimistic (335 $\mathrm{mAh} \mathrm{g}^{-1}$ and $91 \%$ resp.). Corresponding dQ/dV graphs (Fig. 5a) show that no distinguishable peaks are observed for pure DMCbased electrolyte but some undesirable electrochemical process takes place in case of DMC/TMPA-TFSI electrolyte starting from $0.7 \mathrm{~V} \mathrm{vs}$. $\mathrm{Li} / \mathrm{Li}^{+}$. Taking into account the general electrochemical stability of TMPA-TFSI, this may be explained by irreversible co-intercalation of TMPA-cations into the graphite which results in high irreversible capacity [13-16]. At the same time, well-defined single peak is observed for IL-containing electrolytes in presence of FEC. Interestingly, in presence of the same amounts of ILs of different viscosity some shift of FEC-reduction peak to the lower potentials is observed (Fig. 5b). Since the amount of electroactive FEC in all electrolytes is the same, this shift is likely because of IRdrop which is caused by original dissimilarities in

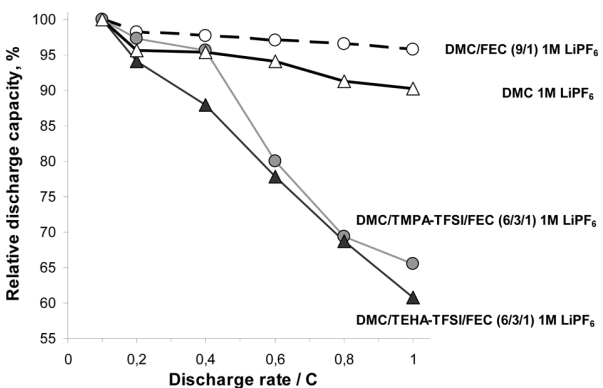

Fig. 6. Rate capability of Li/graphite coin half cells with electrolytes containing 30 vol. \% TMPA-TFSI or TEHATFSI and/or 10 vol. \% FEC.

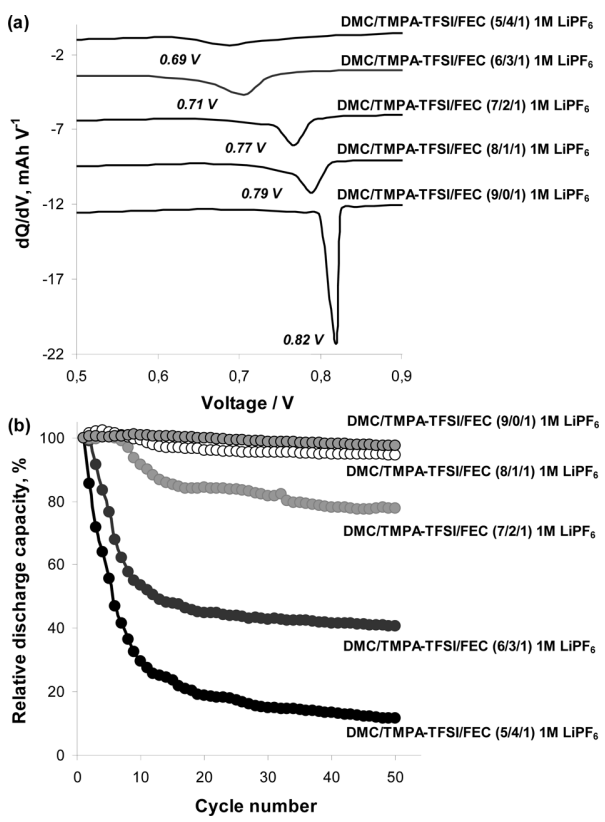

Fig. 7. a) dQ/dV graphs of Li/graphite coin half cells with electrolytes containing 10 vol. \% FEC and different amounts of TMPA-TFSI during $1^{\text {st }}$ cycle at $0.1 \mathrm{C}$; b) discharge capacity retention of $\mathrm{Li} /$ graphite coin half cells with corresponding electrolytes during 50 cycles at $0.5 \mathrm{C}$.

viscosity of introduced ILs and, as a result, of electrolyte mixtures as well.

Fig. 6 displays the comparison of rate capability of Li/graphite coin half cells with electrolytes containing TMPA-TFSI or TEHA-TFSI with those for reference IL-free electrolytes. Even at a quite moderate discharge rates the relative discharge capacity of the cells with IL-based electrolytes decreases significantly, especially in comparison with reference electrolytes. The phenomenon of capacity decrease at 
higher currents also may be explained by higher viscosity of ILs-based electrolytes (for more viscous TEHA-TFSI this effect is more noticeable) [23]. Likely, poor mobility of Li-ions in more viscous electrolytes combined with lowered wettability of active electrodes provide the decline of capacity retention.

The effect of viscosity is clearly shown in Fig. 7. If to increase the amount of IL in electrolyte (for this model experiment TMPA-TFSI was taken), one can observe the shift of characteristic FEC-reduction peak at dQ/dV-graph to the lower potentials (Fig. 7a) which may be the result of reduced ion-mobility and increased IR-drop. At the same time, the presence of TMPA-TFSI in electrolyte mixture causes the capacity fading during cycling at a constant rate of $0.5 \mathrm{C}$ (Fig. 7b). As is seen, the higher the IL-content, the greater the effect. Considering the electrochemical stability of TMPA-TFSI, this capacity loss seems to be caused by increasing viscosity of electrolytes in the investigated series. If so, this phenomenon is expected to be observed for electrolytes with similar content of ILs of different viscosity. In order to check this hypothesis, a range of electrolytes containing 30 vol. \% of different ILs has been tested in graphite/ $\mathrm{LiMn}_{2} \mathrm{O}_{4}$ coin full cells. Decomposition of DMC is observed around $3.5 \mathrm{~V}$ while in presence of 10 vol. \% FEC the SEI-formation is observed at $2.9 \mathrm{~V}$ and this is valid for IL-containing electrolytes also (with small shifts of FEC-reduction peaks; some examples are given in Fig. 8a). These results are in a good agreement with those reported by Choi and co- workers [16]. Table 2 shows the characteristics observed for all electrolyte systems during formation cycle at $0.1 \mathrm{C}$. At this step the irreversible capacity loss for IL-based electrolytes did not exceed $19 \%$ (except PMPL-TFSI) and this value is a little bit higher than for DMC/FEC $(9 / 1 ; \mathrm{v} / \mathrm{v})$ reference electrolyte $(12 \%)$. It seems there is no correlation

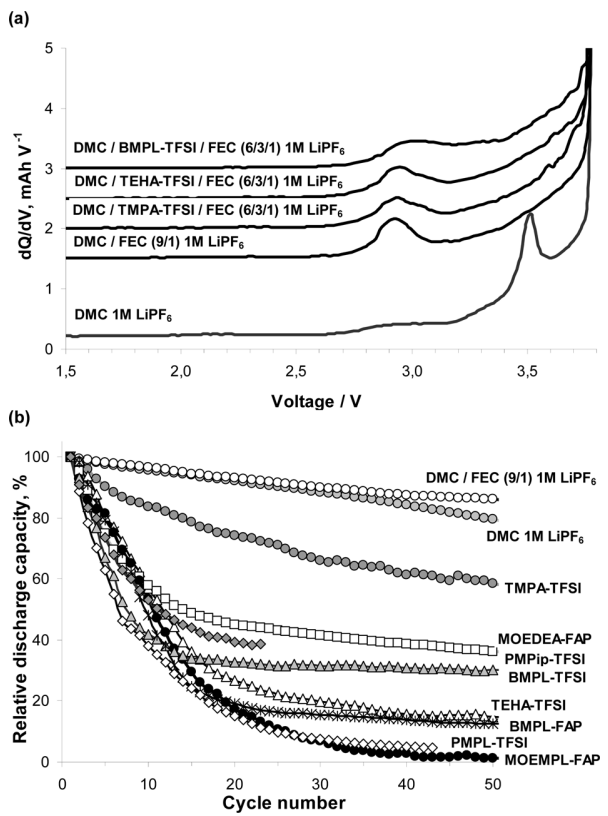

Fig. 8. a) $d Q / d V$ graphs of graphite/LMO coin full cells during $1^{\text {st }}$ cycle at $0.1 \mathrm{C} ; \mathrm{b}$ ) discharge capacity retention of graphite/LMO coin full cells with electrolytes containing 30 vol. $\%$ IL and 10 vol. \% FEC during 50 cycles at $0.5 \mathrm{C}$.

Table 2. Specific charge/discharge capacities, initial coulombic efficiency (ICE) and irreversible capacity of graphite/LMO coin full cells with various DMC-based electrolytes during $1^{\text {st }}$ cycle at $0.1 \mathrm{C}$. All electrolyte solutions contain $1 \mathrm{M} \mathrm{LiPF}_{6}$; in case of IL-containing electrolytes $10 \mathrm{vol}$ \% FEC was added as well.

\begin{tabular}{ccccc}
\hline Electrolyte & Charge capacity/ $\mathrm{mAh} \mathrm{g}^{-1}$ & Discharge capacity/ $\mathrm{mAh} \mathrm{g}^{-1}$ & ICE, \% & Irreversible capacity, \% \\
\hline DMC & 104 & 88 & 85 & 15 \\
DMC/FEC (9/1) & 104 & 92 & 88 & 12 \\
30 vol. \% PMPL-TFSI & 99 & 72 & 73 & 27 \\
30 vol. \% BMPL-TFSI & 103 & 91 & 88 & 12 \\
30 vol. \% PMPip-TFSI & 98 & 80 & 82 & 18 \\
30 vol. \% TMPA-TFSI & 100 & 88 & 88 & 12 \\
30 vol. \% TEHA-TFSI & 103 & 92 & 89 & 11 \\
30 vol. \% MOEDEA-FAP & 106 & 86 & 81 & 19 \\
30 vol. \% MOEMPL-FAP & 97 & 82 & 84 & 16 \\
30 vol. \% BMPL-FAP & 99 & 85 & 86 & 14 \\
\hline
\end{tabular}


between charge/discharge capacity values obtained for IL-based electrolytes and the properties of neat ILs (see Table 1). At the same time, discharge capacity retention differs strongly (Fig. 8b). As is seen, despite the blank electrolytes demonstrate the best cycling performance, some capacity loss during charge/discharge is observed. Probably, this may be attributed to partial decomposition of the solvent at the surfaces of active electrodes (even despite the SEI-formation on the graphite anode at initial cycle) which leads to a smooth increase of an interfacial resistance [36]. For IL-containing mixtures much more significant capacity loss at initial 15-20 cycles takes place. Analogically, main organic solvents (here-carbonates) may partly decompose, however, in case of IL-containing electrolytes this turns to be more critical since it additionally provides (indirectly) the small increase of the content of viscous IL in electrolyte after every cycle. In other words, such IL-based electrolyte mixtures gradually approach to those based on ILs only and this dictates the general characteristics of the cells. In this relation it seems that more careful choice of IL prior to electrolyte formulation is required.

Interestingly, that the expected agreement between ILs viscosity and cycling properties of corresponding electrolytes is not observed (rather, does not hold strictly). Careful inspection of Fig. 8b and comparison of experimental data with physical properties of ILs in Table 1 show that cycling performance of the cells correlates neither with viscosity nor with specific conductivity of neat ILs. However, different ILs have different molar weights and densities which results in different molar ILs concentration, $\mathrm{C}_{\mathrm{IL}}$. Hence, the introducing of $30 \mathrm{vol}$. \% of different ILs into all mixtures is only an apparent uniformity while in fact this produces electrolytes with not only different viscosities but also different concentration of charge carriers of different mobilities (constituent ions of both ILs and $\mathrm{LiPF}_{6}$ ). In this case some more complex criteria is needed for finding the correlation and, likely, it is more correct to operate with $\Lambda \eta$ values known as Walden product [6]; calculated $\Lambda \eta$ values for neat ILs are given in Table 1. If to compare the discharge capacity values for IL-containing electrolytes after some stabilization (approximate plateau is started for almost all electrolytes after 15-20 cycles) with calculated $\Lambda \eta$ values, one can see that there is no direct proportionality between them but

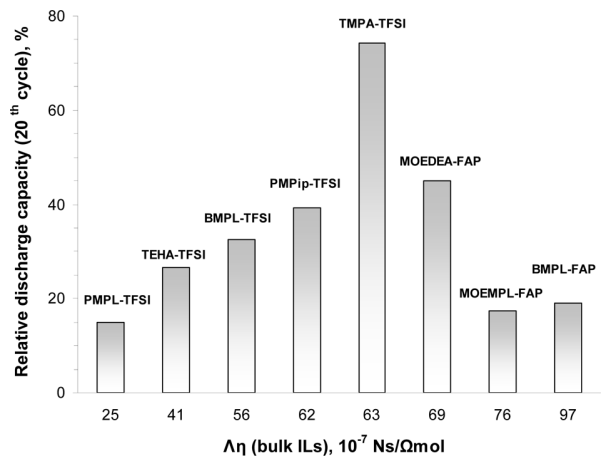

Fig. 9. Relative discharge capacity of graphite/LMO coin full cells with electrolytes containing 30 vol. \% IL and 10 vol. \% FEC after 20 cycles at $0.5 \mathrm{C}$ and calculated values of Walden products for corresponding neat ionic liquids.

rather some distribution takes place (Fig. 9). The highest capacity retention among IL-based electrolytes is observed for TMPA-TFSI while the worst data is obtained for MOEMPL-FAP (or BMPL-FAP) and, surprisingly, for relatively low-viscous PMPLTFSI as well. Comparing TMPA-TFSI with MOEMPL-FAP (or BMPL-FAP), the latter one has incomparably higher viscosity and at the same time the lower $\mathrm{C}_{\mathrm{IL}}$; in case of much less viscous PMPLTFSI, $\mathrm{C}_{\mathrm{IL}}$ and specific conductivity are also lower than those for TMPA-TFSI. Hence, too low or too high Walden product values point to some non-optimality in combination of the quite critical properties. As one can see, viscosity hardly can be appointed as the only parameter to be considered during preliminary screening of suitable ILs. Thus, for example, among investigated structures, MOEDEA-FAP and PMPip-TFSI also may be considered as an appropriate ILs despite their quite high viscosity; this is in agreement with numerous examples of successful utilization of PMPip-TFSI by Matsumoto and coworkers [9-12,21-23]. Of course, the model described implies only one of the possible mechanisms of cells performance degradation [36] and requires an additional experiments. It should be additionally noted that geometry of the cells as well as initial IL's content in electrolyte mixture have an influence on electrochemical performance of LIB and much better characteristics may be achieved (to be published elsewhere).

It should be also emphasized that introduction of ILs into electrolyte mixtures provides a certain enhancement in thermal stability of electrolytes, as 

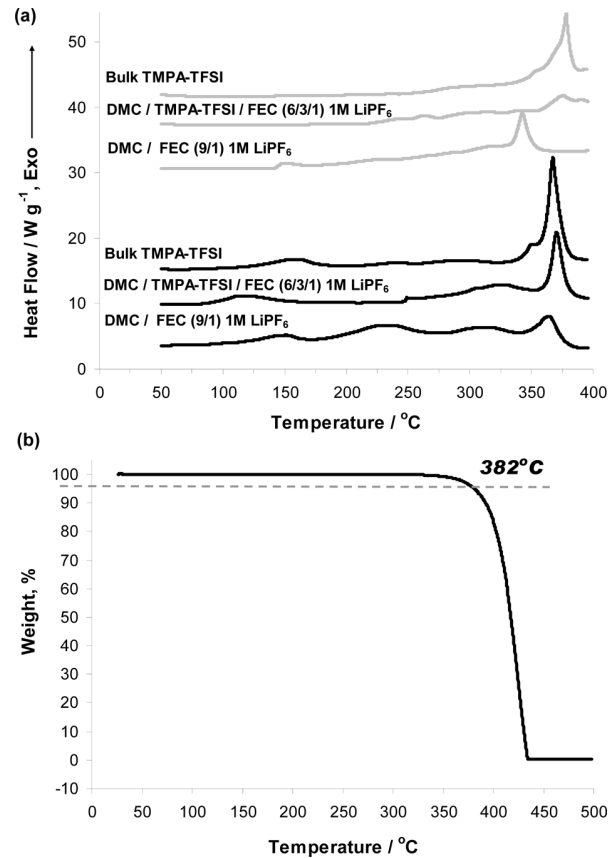

Fig. 10. a) DSC heating curves of lithiated graphite (black lines) and delithiated LMO (gray lines) with electrolytes containing different amounts of TMPA-TFSI; b) TGA curve for neat TMPA-TFSI.

expected. Fig. 10a depicts the DSC heating curves for lithiated graphite or delithiated $\mathrm{LiMn}_{2} \mathrm{O}_{4}$ with different electrolyte compositions. For a model experiment, graphite (or $\mathrm{LiMn}_{2} \mathrm{O}_{4}$ ) has been charged in a well-described standard $1 \mathrm{M} \mathrm{LiPF}_{6}$ solution in $\mathrm{EC} /$ $\operatorname{EMC~(3/7,~v/v)~[25-37].~In~comparison~with~refer-~}$ ence IL-free electrolyte, the presence of TMPA-TFSI does not affect the thermal decomposition of SEI at lithiated graphite surface (first exothermic peak around $150^{\circ} \mathrm{C}$ ) but suppresses the thermal reactions between electrolyte and lithiated graphite (two consecutive peaks around 230 and $320^{\circ} \mathrm{C}$ ). Generally, the undesired thermal reactions between charged electrode material and $\mathrm{LiPF}_{6}$-containing electrolyte are diminished by TMPA-TFSI for $\mathrm{LiMn}_{2} \mathrm{O}_{4}$ as well [38]. Notably, that in both cases, lithiated graphite and delithiated $\mathrm{LiMn}_{2} \mathrm{O}_{4}$, the increase of exothermic peaks around $370-380^{\circ} \mathrm{C}$ is observed and the effect is higher with the increase of TMPA-TFSI content. This is probably associated with the thermal decomposition of TMPA-TFSI at around $380^{\circ} \mathrm{C}$ (see corresponding TGA-curve in Fig. 10b). Hence, the thermal stability of ILs at high temperatures seems to be an important factor while a proper reduce of exothermic heat evolution below $350^{\circ} \mathrm{C}$ may be already achieved.

\section{Conclusions}

Eight quaternary ammonium-based room temperature ionic liquids, known as electrochemically stable salts, have been examined as components of traditional carbonate electrolytes for Li-ion batteries. To prevent the irreversible loss of capacity at initial cycles, the stable SEI layer should be provided and FEC may be an appropriate additive for this. Electrochemical performance of coin-type Li/graphite half cells and graphite $/ \mathrm{LiMn}_{2} \mathrm{O}_{4}$ full cells with IL-containing electrolytes strongly depends both on the actual amount of IL used and the combination of its physicochemical properties (viscosity, specific conductivity, density, etc.). Rate capability of coin cells with IL-containing electrolytes is lower than for standard carbonate IL-free electrolytes, likely, because of the viscosity effect. During continuous charge/discharge cycling at $0.5 \mathrm{C}$ rate the lowest capacity fading is observed for $1 \mathrm{M} \mathrm{LiPF}_{6}$ DMC-based electrolyte containing 10 vol. \% FEC and 30 vol. \% TMPA-TFSI (ca. $60 \%$ of initial discharge capacity after 50 cycles); for similar electrolyte compositions with more viscous (or less conductive) ILs the cycle life is significantly lower. By means of DSC it has been demonstrated that presence of TMPA-TFSI provides noticeable reduce of exothermic heat evolution for electrolyte in contact with lithiated graphite or delithiated $\mathrm{LiMn}_{2} \mathrm{O}_{4}$.

\section{Acknowledgement}

The authors are grateful to the Samsung SDI Corporation for the support of this work.

\section{References}

[1] T. Tanaka, K. Ohta and N. Arai, J. Power Sources, 9798, 2 (2001).

[2] S. Patoux, L. Daniel, C. Bourbon, H. Lignier, C. Pagano, F. Le Cras, S. Jouanneau and S, Martinet, $J$. Power Sources, 189, 344 (2009).

[3] P. G. Balakrishnan, R. Ramesh and T. P. Kumar, J. Power Sources, 155, 401 (2006).

[4] G. Gachot, S. Grugeon, M. Armand, S. Pilard, P. Guenot, J.-M. Tarascon and S. Laurelle, J. Power Sources, 178, 409 (2008).

[5] K. Xu, Chem. Rev., 104, 4303 (2004). 
[6] M. Galinski, A. Lewandowski and I. Stepniak, Electrochim. Acta, 51, 5567 (2006).

[7] P. Wasserscheid and T. Welton (Eds.), Ionic Liquids in Synthesis, $2^{\text {nd }} e d$., Wiley-VCH: New York (2007).

[8] H. Ohno (Ed.), Electrochemical Aspects of Ionic Liquids, John Wiley and Sons Inc., Hoboken, NJ (2005).

[9] H. Sakaebe, H. Matsumoto and K. Tatsumi, Electrochim. Acta, 53, 1048 (2007).

[10] A. Lewandowski and A. Swiderska-Mocek, J. Power Sources, 194, 601 (2009).

[11] H. Sakaebe and H. Matsumoto, Electrochem. Commun., 5, 594 (2003).

[12] H. Matsumoto, H. Sakaebe and K. Tatsumi, J. Power Sources, 146, 45 (2005).

[13] H. Zheng, K. Jiang, T. Abe and Z. Ogumi, Carbon, 44, 203 (2006).

[14] E. Markevich, V. Baranchugov, G. Salitra, D. Aurbach and M. A. Schmidt, J. Electrochem. Soc., 155, A132 (2008).

[15] T. E. Sutto, T. T. Duncan and T. C.Wong, Electrochim. Acta, 54, 5648 (2009).

[16] N. S. Choi, Y. Lee, S. S. Kim, S. C. Shin and Y. M. Kang, J. Power Sources, 195, 2368 (2010).

[17] M. Holzapfel, C. Jost and P. Novak, Chem. Commun., 2098 (2004)

[18] T. Sato, T. Maruo, S. Marukane and K. Takagi, J. Power Sources, 138, 253 (2004).

[19] A. Lewandowski and A. Swiderska-Mocek, J. Power Sources, 171, 938 (2007).

[20] A. Lewandowski and A. Swiderska-Mocek, J. Power Sources, 194, 502 (2009).

[21] H. Sakaebe, H. Matsumoto and K. Tatsumi, J. Power Sources, 146, 693 (2005).

[22] H. Matsumoto, H. Sakaebe, K. Tatsumi, M. Kikuta, E. Ishiko and M. Kono, J. Power Sources, 160, 1308 (2006).

[23] H. Nakagawa, Y. Fujino, S. Kozono, Y. Katayama, T. Nukudaa, H. Sakaebe, H. Matsumoto and K. Tatsumi, $J$. Power Sources, 174, 1021 (2007).

[24] A. Guerfi, M. Dontigny, P. Charest, M. Petitclerc, M.
Lagacé, A. Vijh and K. Zaghib, J. Power Sources, 195, 845 (2010).

[25] I. A. Profatilova, N. S. Choi, S. W. Roh and S. S. Kim, J. Power Sources, 192, 636 (2009).

[26] R. McMillan, H. Slegr, Z. X. Shu and W. Wang, J. Power Sources, 81-82, 20 (1999).

[27] I. A. Profatilova, S. S. Kim and N. S. Choi, Electrochim. Acta, 54, 4445 (2009).

[28] ZD. R. McFarlane, J. Sun, J. Golding, P. Meakin and M. Forsyth, Electrochim. Acta, 45, 1271 (2000).

[29] H. Matsumoto, M. Yanagida, K. Tanimoto, K. Kojima, Y. Tamiya and Y. Miyazaki, Chem. Lett., 922 (2000).

[30] Data reported by manufacturer (Merck KGaA) in catalogues and brochures.

[31] N. V. Ignat'ev, U. Welz-Biermann, A. Kucheryna, G. Bissky and H. Willner, J. Fluorine Chem., 126, 1150 (2005).

[32] L. Larush, V. Borgel, E. Markevich, O. Haik, E. Zinigrad, D. Aurbach, G. Semrau and M. Schmidt, J. Power Sources, 189, 217 (2009).

[33] X. Wang, E. Yasukawa and S. Mori, Electrochim. Acta, 45, 2677 (2000); T. Kawamura, T. Tanaka, M. Egashira, I. Watanabe, S. Okada and J. Yamaki, Electrochem. Solid-State Lett., 8, A459 (2005).

[34] B. Garcia and M. Armand, J. Power Sources, 132, 206 (2004); J. Mun, T. Yim, C. Y. Choi, J. H. Ryu, Y. G. Kim and S. M. Oh, Electrochem. Solid-State Lett., 13, A109 (2010); P.-S. Kühnel, M. Lübke, M. Winter, S. Passerini and A. Balducci, J. Power Sources, 214, 178 (2012).

[35] S. S. Zhang and T. R. Jow, J. Power Sources, 109, 458 (2002); S.-W. Song, T. J. Richardson, G. V. Zhuang, T. M. Devine and J. W. Evans, Electrochim. Acta, 49, 1483 (2004).

[36] T. Osaka, S. Nakade, M. Rajamäki and T. Momma, $J$. Power Sources, 119-121, 929 (2003).

[37] N. S. Choi, I. A. Profatilova, S. S. Kim and E.-H. Song, Thermochim. Acta, 480, 10 (2008).

[38] H. F. Xiang, H. Wang, C. H. Chen, X. W. Ge, S. Guo, J. H. Sun, W. Q. Hu, J. Power Sources, 191, 575 (2009). 